Pakistan Journal of Education

Vol. 36, No. 3, 2019, 1-18

\title{
Acute Performance Estimation of Students Using Quantile Regression Approach (A Case Study of Lahore)
}

\author{
Sunaina Ishtiaq* \\ Yasar Mahmood \\ Hina Khan ${ }^{*}$
}

\begin{abstract}
Extreme behavior (Performance) of students is inclined by number of factors which are must be painted for important policy implications. This study states that CGPA is the most important system to detect student performance. Data on CGPA has been collected from B.A/B.Sc (Hons.) of 32 private and public universities of Lahore. Generally, researchers investigate an average performance of the students with classical methods of simple linear regression. This approach does not give complete picture of different variables influencing student performance from corner to corner. Quantile regression introduces information across the whole distribution of the student's achievements. Study furnishes that students performance strongly affected by father's education. Student's gender, passion for fashion, and mother's job are significant factors. Class participation is found as a magical variable that has positive impact on student performance at all quantiles. The quantile estimate of student performance shows that effect of the urban-rural difference is significant factor. The study clearly shows for high performance students, factors like mother occupation, father education, gender and area become insignificant at high quantiles. The results highlight that quantile regression model is a useful technique to examine information than ordinary least squares. It also depicts that ordinary least squares underestimated and overestimated the Quantile regression at different quantiles.
\end{abstract}

Keywords: acute performance, cumulative grade point average (CGPA), peer-group effects, quantile regression, ordinary least square

\footnotetext{
${ }^{*}$ M.Phil Scholar, Email: punjabgroupofcolleges6@gmail.com

${ }^{* *}$ Lecturer, Email: syed.yasar@gcu.edu.pk (Corresponding Author)

*** Assistant Professor, Email: hinakhan@gcu.edu.pk
} 


\section{Introduction}

The word "Education" was consequent from the Latin word "educare" meaning to transport, to direct, to lift up, and to teach. The achievement of a student depends on various elements such as gender, residential area, father education level, mother occupation, number of siblings of student, government employment policy (Hijaz \& Naqvi, 2006; Diaz, 2003). Higher level of education has direct link with enhanced financial and mental state. Such as more income leads to better communal hold and networking (Boushey, 2005). Oettinger (1999) explored that students who handed over more homework had high marks. Study of Hanushek (1986) gave the evidence that student perform better with their teacher who have useful characteristics. Numerous factors are generally link to academic achievement including student factors, family related factors and peer group factors (Crosnoe et al., 2004). Parents with a high socio-economic position are more likely to cooperate and have fun with their offspring (Marmot \& Michael, 2004). Diaz (2003) made it clearer by saying, "Educational circumstance attributed to the family is away from all uncertainty, or discussion, as being aware from the significance of the parent's responsibility in the development and learning growth of their children". Moreover, parent's participation in their child learning increases the velocity of educational success of their kid (Furstenberg \& Hughes, 1995). The communal support has a critical part for the achievement objectives of students at school (Goddard, 2003). According to Mobegi et al. (2010), government should take up its responsibility as guarantee officers in their institutes and make sure that there is sufficient departmental management. It is a keen responsibility of good government to provide facilities in poor areas to improve education system (Mobegi et al., 2010; Orodho, 2014).

\section{Factors under Study}

The set of variables that are under consideration, illuminating the performance are classified into further categories such as: Student profile, peer group, student's personal activities, teacher's related factors, and government factors are the factors that affect a student's performance.

a) Student profile

b) $\quad$ Peender, Agroup

Father's profession, Parent's education, Monthly earnings of the respondent's family, Number of siblings and their education 
c) Student's personal activities

Academic performance in previous semester (CGPA), Pocket money of the student, Sports participation, internet and cell phone use, canteen visiting hours, Study hours other than lectures, Passion for fashion, Gathering with friends, Combine study, Part time job

d) Factors related to teachers

Regular and punctual Class discipline, well prepared lectures, Strong communication skill, Encourage class participation, Behave politely with students, unbiased attitude, Fair in marking, Complete course in time

\section{Literature Review}

Koenker and Bassett (1978) introduced quantile regression as an expansion of classical least squares estimation of conditional mean models. Conclusion indicated that quantile regression is progressively present a complete regression picture. Other conditional quantile functions are predicted by reducing an asymmetrically weighted sum of absolute errors.

$$
\begin{aligned}
& Q_{n}(\tau) \\
& =\min \left\{\sum_{\mathrm{i}: Y \geq \xi} \tau\left|Y_{i}-\xi\right|\right. \\
& \left.+(1-\tau) \sum_{i: Y<\xi}(1-\tau)\left|Y_{i}-\xi\right|\right\} \\
& \quad=\min _{\xi \in \mathbb{R}}\left\{\sum_{i} \rho_{\tau}\left(Y_{i}-\xi\right)\right\}
\end{aligned}
$$

Where $\rho_{\tau}(\mu)=\mu(\tau-\mathrm{I}(\mu<0)$ is the called check function or piece wise function which takes positive and negative values.

$$
\rho_{\tau}(\mu)=\left\{\begin{array}{lll}
\mu(\tau-1) & \text { if } & \mu<0 \\
\mu(\tau) & \text { if } & \mu \geq 0
\end{array}\right.
$$

Quantile regression expands this effortless formulation to allow for $\mathrm{X}$ regressors. We suppose a linear specification for the conditional quantile of the response variable $Y$ given values for the $p$-vector of independent variables $\mathrm{X}$. The quantile regression estimator for quantile $\tau$ reduces the objective function: 


$$
\begin{array}{r}
\mathrm{Q}\left(\hat{\beta}_{\tau}\right)=\min _{\beta_{\tau} \in \mathbb{R}}\left\{\sum_{\mathrm{i}} \rho_{\tau}\left(\mathrm{Y}_{\mathrm{i}}-\mathrm{X}_{\mathrm{i}}^{\mathrm{T}}\left(\beta_{\tau}\right)\right)\right\} \\
\mathrm{Q}\left(\hat{\beta}_{\tau}\right)=\min \left\{\sum_{\mathrm{i}: \mathrm{Y} \geq \mathrm{X}_{\mathrm{i}}^{\mathrm{T}}\left(\beta_{\tau}\right)} \tau\left|\mathrm{Y}_{\mathrm{i}}-\mathrm{X}_{\mathrm{i}}^{\mathrm{T}}\left(\beta_{\tau}\right)\right|\right. \\
\left.+(1-\tau) \sum_{\mathrm{i}: \mathrm{Y}_{\mathrm{X}} \mathrm{X}_{\mathrm{i}}^{\mathrm{T}}\left(\beta_{\tau}\right)}(1-\tau)\left|\mathrm{Y}_{\mathrm{i}}-\mathrm{X}_{\mathrm{i}}^{\mathrm{T}}\left(\beta_{\tau}\right)\right|\right\}
\end{array}
$$

This non-differentiable function and is reduced via the simple method, which is guaranteed to yield a solution in a finite number of iterations.

Koenker and Bassett (1978) derived asymptotic normality results for the quantile regression estimator in the i.i.d. setting.

Where

$$
\sqrt{\mathrm{n}(\hat{\beta})}(\tau)-\beta(\tau)) \sim \mathrm{N}\left(0, \tau(1-\tau) \mathrm{s}(\tau)^{2} \mathrm{~J}^{-1}\right)
$$

$$
\begin{array}{r}
J=\lim _{n \rightarrow \infty} \sum_{\substack{i \\
s}} X^{T} / n=\lim _{n \rightarrow \infty}\left(X X^{T} / n\right) \\
=F^{-1}(\tau)=1 / f\left(F^{-1}(\tau)\right)
\end{array}
$$

While, $s(\tau)$ is termed the sparsity function by Tukey(1965) and the quantile density function by Parzen(1979). Note that the i.i.d. error assumption implies that $s(\tau)$ does not depend on X. In fact, the expression for the asymptotic covariance is similar to the ordinary least squares covariance in the i.i.d. setting.

Practically to obtain consistently of data since it involves conditional densities of the error terms is quite difficult. So, the following estimation methods provided by Koenker (2005) are employed to get the asymptotic variance covariance matrices. Whereas the asymptotic theory of $\widehat{\beta}(\tau)$ is derived from the practical non-IID setting.

The limiting covariance matrix $\sqrt{\mathrm{n}(}(\hat{\beta})(\tau)-\beta(\tau))$ of takes the form of a Huber (1967) sandwich,

Where

$$
\sqrt{\mathrm{n}(}(\widehat{\beta})(\tau)-\beta(\tau)) \sim \mathrm{N}\left(0, \tau(1-\tau) \mathrm{H}_{\mathrm{n}}{ }^{-1} \mathrm{~J}_{\mathrm{n}} \mathrm{H}_{\mathrm{n}}{ }^{-1}\right)
$$

$$
\begin{array}{r}
\mathrm{J}_{\mathrm{n}}(\tau)=\mathrm{n}^{-1} \sum_{\mathrm{i}=1}^{\mathrm{n}} \mathrm{x}_{\mathrm{i}} \mathrm{x}_{\mathrm{i}}^{\mathrm{T}} \\
\mathrm{H}_{\mathrm{n}}(\tau)=\mathrm{n}^{-1} \sum_{\mathrm{i}=1}^{\mathrm{n}} \mathrm{x}_{\mathrm{i}} \mathrm{x}_{\mathrm{i}}^{\mathrm{T}} \mathrm{f}_{\mathrm{i}}(\xi(\tau))
\end{array}
$$


With $f_{i}(\xi(\tau))$ being the conditional density of the response $y_{i}$ evaluated at the $\tau$ th conditional quantile where $\xi(\tau)$ is the $\tau$-th conditional quantile function .In the IID case, these $\mathrm{f}_{\mathrm{i}} \mathrm{s}$ are the same and straightforward to find in asymptotic theory. However, in the non-IID case, it is needed to consider more aspects.

Gilbert et al. (2002) and Eric et al. (1998) estimated the association among school quality factors and performance of student. Analysis conducted on factors such as math test score, gender, race, background, presence of father and mother in the family circle, parent's education, family income, family size, area of residence, and region. Sheng et al. (2010), Nicole (2005) and Tian (2004) discussed about family background factor that can be a very essential component of a person's life. One of the key objects of this paper is to examine whether the family background factors change performance on mathematical achievement of the stronger students in the identical way that weaker students are exaggerated. Additionally, quantile regressions put forward the idea that peer effects favor the lowability students. Changhui (2006) stated endogenous structure of peer groups frequently curse studies on classmate peer effects. It was examine the existence and comprehensive formation of academic connections among classroom peers and student performance. Quantile regressions expose that weak students relate more strongly with other weak students. Zoltán et al. (2011) uttered that preceding research offer uncertain results on the relationship between student performance and family background. In first step quantile regression model has been used to estimate the family surroundings effect at different position of the distribution. In second step, association among estimates and the mean achievement has analyzed. Kimani et al. (2013), Nonis et al. (2006)\& Jennifer et al. (2006) examined the connection between teacher's demographic personality, classroom instructional performance and student's intellectual achievement. Simple linear regression and one-way ANOVA (Analysis of Variance) are used to test the association among the chosen variables and student performance. The study demonstrated that teacher's age, sex, specialized education and teaching skill are not considerably connected to educational success. Teacher's work has important and encouraging association with student's academic accomplishment in secondary schools. Teacher's daily teaching workload, management of students in classroom, coursework, assessment of 
student's, condition of individual attention to weak students, and time of closure of course outline effects student's academic accomplishment.

\section{Significance of the Study}

Several studies have carried out to explore the effect of different factors on student performance by using different statistical techniques such as simple linear regression, multiple linear regressions and logistic regression etc. However, no research is carried out in Pakistan that covers out different quantiles that is what are the significant factors where $10 \%, 20 \%$ of the student's CGPA is below certain CGPA point? The measures of study about student performance would help the teachers to select appropriate techniques for low and high performers.

\section{Objectives of the Study}

i. The study aims to explore the difference between linear regression based on mean and quantile regression based on quantiles relative to the study.

ii. To study which variables are significant and insignificant for good performance students and which variables put effect on low performance students.

iii. To inspect the effect of different variables vary from corner to corner at quantiles in the conditional distribution of performance.

\section{Research Methodology}

Students of B.A/B.Sc. (HONS.) of all public and private universities of Punjab were taken as target population because it is referred to the population about which researcher is interested to draw conclusion. Sampled population is the number of B.A/B.Sc. (HONS.) students of universities in Lahore. Only the universities with coeducation system were taken into consideration because most of them have experienced both type of institutions and they can give significant response to the questionnaire. In order to decide the total sample size, three factors were considered with $95 \%$ confidence level, $65 \%$ of the students responded that they are satisfied with their performance (taken from the pre-test) and $\pm 5 \%$ precision rate is considered to determine the sample size formula presented by (Cochran, 1977)

$$
n=\frac{Z_{\alpha / 2}^{2} \hat{p} \hat{q}}{e^{2}}
$$


After using information in above formula, a sample of size, $n=\frac{(1.96)^{2}(0.65)(0.35)}{(0.05)^{2}}=349$ students interviewed from different universities. Questionnaire has designed after reading enough literature and some new factors are included that most probably effect student performance. A pilot survey is conducted before the final stage of collecting information. It helped to remove ambiguity and addition of new question in questionnaire. For checking the reliability of the responses according to the designed questionnaire, reliability analysis is executed and the reliability index is 0.705 .

\section{Selection of Universities}

At this stage, number of universities decided in which a sample of 350 students allocated. Students of graduate level considered as strata from selected universities.

Number of universities $=\frac{n}{1+\left(\frac{n}{N}\right)}($ Cochran, 1977)

Where, $n=$ Sample size

$$
N=\text { Total no. of universities }
$$

\section{Allocation of Sample Size}

Number of universities selected $=k=\frac{350}{1+\left(\frac{350}{36}\right)}=32.64$

As total number of students and any other particular information, regarding students in universities are not available, so equal allocation of sample is carried out.

$$
n_{i}=\frac{n}{k}=\frac{350}{32}=10.9
$$

Finally, due to rounding off number of university and sample size with equal allocation, the resultant sample size does not match with obtained size. So, a sample of 350 (one extra questionnaire to be filled than the obtained sample size) has been decided for further filling of questionnaires and analysis.

\section{Empirical Model}

This research take factors that include class participation, fashion, father education, mother occupation, sibling, student gender, Government, 
and area that put an influence on the CGPA of students. The subsequent function state the relationship

CGPA

$=f$ (class participation, fashion, father education, mother occupation, sibling, student gender, Government, area)

$$
C G P A=f\left(F a_{i}, F E_{i}, M E_{i}, U R_{i}, G, C P_{i}, N S_{i}, S G_{i}\right)+\varepsilon_{i}
$$

\section{Data Analysis and Discussion}

Table1 shows equal number of private and government universities has been taken. Both have equal proportion of $50 \%$ for taking information for further analysis. $21.1 \%$ students do not participate in class where as $78.9 \%$ students do participate in class. $51.1 \%$ students do not join any society or union in university while $48.9 \%$ join such societies. $88 \%$ students do not smoke while $12 \%$ students do smoke. 21.7 $\%$ students do not complete their assignment on their own while $78.3 \%$ students do. This means many students are independent in study work. $42 \%$ of students are not passionate towards fashion whereas $57.7 \%$ have passion for fashion. It means students at universities are much conscious about their dressing etc. According to $35.1 \%$, student gender do not put effect on student performance while $60 \%$ says yes. $39.1 \%$ students think teacher salary does not put any effect on student performance whereas $60.9 \%$ says yes it has affect. $39.4 \%$ students opted that class size do not effect student performance but $60.6 \%$ student said it is important. $80.9 \%$ students mother is a housewife and be at home whereas $19.1 \%$ students are those whose mother is an earning lady and do job. According to 39.4 $\%$ students, distance between home and institute does not affect their performance whereas $65.1 \%$ said yes. According to $37.1 \%$ students, teacher gender does not affect student performance while $62.9 \%$ negate it. It means a greater proportion of students believe teacher gender influence their performance. 
Table 1:

Descriptive Statistics of Variables

\begin{tabular}{lcc}
\hline \multirow{2}{*}{ Question Statement } & \multicolumn{3}{c}{ Percentages } \\
\cline { 2 - 4 } & Yes & No \\
\hline Do you participate in you class? & 78.9 & 21.1 \\
Do you participation in unions? & 48.9 & 51.1 \\
Do you smoke and take narcotic? & 12 & 88 \\
Do you think student gender influence on performance? & 64 & 35.1 \\
Do you done your assignment on your own? & 78.3 & 21.7 \\
Do you have Passion for fashion? & 57.7 & 42.3 \\
Do you think teacher salary's effects on student & 60.9 & 39.1 \\
performance? & 60.6 & 39.4 \\
Does class size effects your performance? & 67.1 & 32.9 \\
$\begin{array}{l}\text { Does your institute arrange scholarships on merit? } \\
\text { Does your institute arrange seminar's to enhance student }\end{array}$ & 67.1 & 32.9 \\
$\begin{array}{l}\text { vision? } \\
\text { Does your institute encourage educational atmosphere? }\end{array}$ & 75.4 & 24.6 \\
$\begin{array}{l}\text { Does your ethical values are appreciated in your } \\
\text { institution? }\end{array}$ & 76 & 24 \\
$\begin{array}{l}\text { Does your institute organize Quiz competitions, debates, } \\
\text { and sports? }\end{array}$ & 12 & 88 \\
$\begin{array}{l}\text { Do you think Government has proper employment policy? } \\
\text { Do you discuss your problems with your teacher }\end{array}$ & 42 & 58 \\
$\begin{array}{l}\text { separately? } \\
\text { Do you think distance from home to institute effects on } \\
\text { performance? }\end{array}$ & 58.6 & 41.4 \\
$\begin{array}{l}\text { Do you think teacher gender influences student } \\
\text { performance? }\end{array}$ & 34.9 & 65.1 \\
\hline
\end{tabular}

\section{Quantile Regression Analysis}

Results in table 2 show that mainly appealing question linked to the subject of urban-rural difference that can found from area variable. The OLS estimates show a significant coefficient of 0.124 for the indicator of urban-rural difference, indicates that the mean performance of the urban students is 0.124 significantly higher than the performance of rural students when the maximum CGPA is 3.57. Whereas, quantile 
estimate of student performance shows that less effect of the urban-rural difference lies in 0.1 quantile and it is insignificant as well. While the high effect is on 0.9 quantile which is approximately equal to OLS results. Class participation is found as a magical variable that has positive significant impact on student performance overall at all quantiles. It means class participation put larger impact on the students who have $90 \%, 80 \%, 70 \%, 60 \%$ and $50 \%$ students above them as compare to those who have $10 \%, 20 \%$ and $30 \%$ students below them. This mean as low performance students do class participation it make their concepts clear and increase the probability to give answer in exams, projects, assignment, which eventually lead to good performance. While this variable is significant according to OLS. It means when student do class participation it put positive constructive effect on student performance. For family related factors, the OLS estimation indicates that the number of siblings has a significantly negative effect on student performance. Analogous results are bringing into being from quantile regression where with high performers, this degree of upshot cuts as quantile rises. At lower quantiles this is putting very less influence on student performance. OLS underestimates QRM results. Coefficients of government employment policy are showing an increasing pattern as quantiles increases. The students' family background indicators expose some important findings, particularly in terms of the father's educational level. The estimated results from the OLS models indicate that the mean effect of the father's educational levels is negatively significant by lack of 0.182 points. According to QRM, father's educational level is negatively associated with student performance at all quantiles. At all quantile OLS underestimates QRM estimates. Mother's full-time job carries out negative influences on her children's performance by 0.121 points from OLS regression. According to QRM, mother employment status is influencing in a downbeat manner with student performance. On remaining quantiles OLS underestimate QRM. According to OLS student gender from base category female to male, lower the performance of student by 0.081 points. Student's gender robustly affects student academic performance as girls performing better cumulatively as compare to male students. OLS estimates overestimate the QRM. 
Table 2:

Comparison of OLS and QRM

\begin{tabular}{|c|c|c|c|c|c|c|c|c|c|c|}
\hline \multirow{2}{*}{ Variables } & \multirow{2}{*}{ OLS } & \multicolumn{9}{|c|}{ Quantiles } \\
\hline & & 0.1 & 0.2 & 0.3 & 0.4 & 0.5 & 0.6 & 0.7 & 0.8 & 0.9 \\
\hline $\mathrm{C}$ & 3.169 & 2.949088 & 2.88304 & 2.91612 & 3.05881 & 3.03836 & 3.02633 & 3.08029 & 3.10417 & 3.147417 \\
\hline area & 0.124 & 0.062899 & 0.06864 & 0.08654 & 0.14545 & 0.15443 & 0.18772 & 0.15294 & 0.19083 & 0.19 \\
\hline $\begin{array}{l}\text { Class } \\
\text { Participation }\end{array}$ & 0.181 & 0.256678 & 0.23216 & 0.25187 & 0.18218 & 0.21787 & 0.18557 & -0.0809 & 0.13083 & 0.128146 \\
\hline Fashion & -0.154 & -0.12023 & -0.1134 & -0.1208 & -0.1877 & -0.1856 & -0.1786 & 0.12794 & -0.0858 & -0.05126 \\
\hline $\begin{array}{l}\text { Father } \\
\text { Education }\end{array}$ & -0.182 & -0.09691 & -0.1341 & -0.1594 & -0.1862 & -0.1587 & -0.132 & -0.1185 & -0.1725 & -0.21967 \\
\hline Govt & -0.077 & -0.24746 & -0.2572 & -0.14 & -0.0297 & -0.0374 & -0.0038 & -0.1488 & -0.0575 & -0.05828 \\
\hline $\begin{array}{l}\text { Mother } \\
\text { Occupation }\end{array}$ & -0.121 & -0.00707 & -0.0927 & -0.1008 & -0.17 & -0.1654 & -0.1509 & -0.0106 & -0.1117 & 0.107815 \\
\hline Sibling & -0.034 & -0.05766 & -0.0532 & -0.0557 & -0.0544 & -0.0384 & -0.033 & -0.1565 & -0.0225 & -0.01007 \\
\hline $\begin{array}{l}\text { Student } \\
\text { Gender }\end{array}$ & -0.081 & -0.03039 & -0.0302 & -0.0817 & -0.0624 & -0.0816 & -0.0747 & 0.00677 & -0.0517 & -0.03848 \\
\hline Total & -0.008 & -0.01218 & 0.00728 & 0.00893 & 0.00693 & 0.00639 & 0.0062 & -0.0209 & 0.00583 & 0.000331 \\
\hline
\end{tabular}

\section{Slope Equality Test}

The top section of the table 3 shows the equation measurement, and the Wald test summary. Expectedly, it can be seen that the chistatistic value is 74.42606 and statistically significant. Therefore, conclusion is that coefficients are different across quantile values and conditional quantiles are not equal. Second section provides evidence about non-equality of variables coefficients individually at different quantiles by rejecting null hypothesis. 
Table 3 :

Quantile Slope Equality Test

\begin{tabular}{clrrr}
\hline \multicolumn{2}{c}{ Test Summary } & Chi-Sq. Statistic & Chi-Sq.d.f. & P-Value \\
Wald Test & 74.42606 & \multicolumn{1}{c}{16} & 0.0000 \\
\hline Quantiles & \multicolumn{1}{c}{ Variable } & Restr. Value & Std. Error & Prob. \\
$0.25,0.5$ fashion & 0.110857 & 0.039076 & 0.0046 \\
& area & -0.077000 & 0.039259 & 0.0498 \\
Govt. & -0.156286 & 0.054045 & 0.0038 \\
Mothocp father & 0.024714 & 0.048615 & 0.6112 \\
education & -0.107000 & 0.064139 & 0.0953 \\
sibling & -0.015286 & 0.012488 & 0.2209 \\
studgen & 0.021714 & 0.042735 & 0.6114 \\
classpart & 0.067286 & 0.057841 & 0.2447 \\
fashion & -0.080105 & 0.037519 & 0.0328 \\
area & -0.020632 & 0.033158 & 0.5338 \\
govt & 0.005158 & 0.032609 & 0.8743 \\
mothocp & 0.029684 & 0.042704 & 0.4870 \\
father & 0.037263 & 0.041176 & 0.3655 \\
education & -0.024526 & 0.010381 & 0.0181 \\
sibling & 0.014526 & 0.042539 & 0.7327 \\
studgen & 0.007263 & 0.050981 & 0.8867 \\
classpart & & &
\end{tabular}

\section{Quantile Symmetry}

The test applied in table 4 compares estimates at first and third quartile with the median specification. At the same time, it provides a strong evidence for slope coefficients that these are not constant across quantiles. Again, it can be seen that there is no evidence of departures from symmetry.

Table 4:

Symmetric Quantiles Test

\begin{tabular}{|c|c|c|c|c|}
\hline Test Summary & & $\begin{array}{l}\text { Chi-Sq. } \\
\text { Statistic }\end{array}$ & Chi-Sq. d.f. & Prob. \\
\hline Wald Test & & 0.080472 & 1 & 0.7767 \\
\hline \multicolumn{5}{|c|}{ Restriction Detail: $b(\tau)+b(1-\tau)-2 * b(.5)=0$} \\
\hline $\begin{array}{l}\text { Quantiles } \\
0.25,0.75\end{array}$ & $\begin{array}{c}\text { Variable } \\
\text { C }\end{array}$ & $\begin{array}{r}\text { Restr. Value } \\
-0.027511\end{array}$ & $\begin{array}{r}\text { Std. Error } \\
0.096982\end{array}$ & $\begin{array}{l}\text { Prob. } \\
0.7767\end{array}$ \\
\hline
\end{tabular}




\section{Quantile Process}
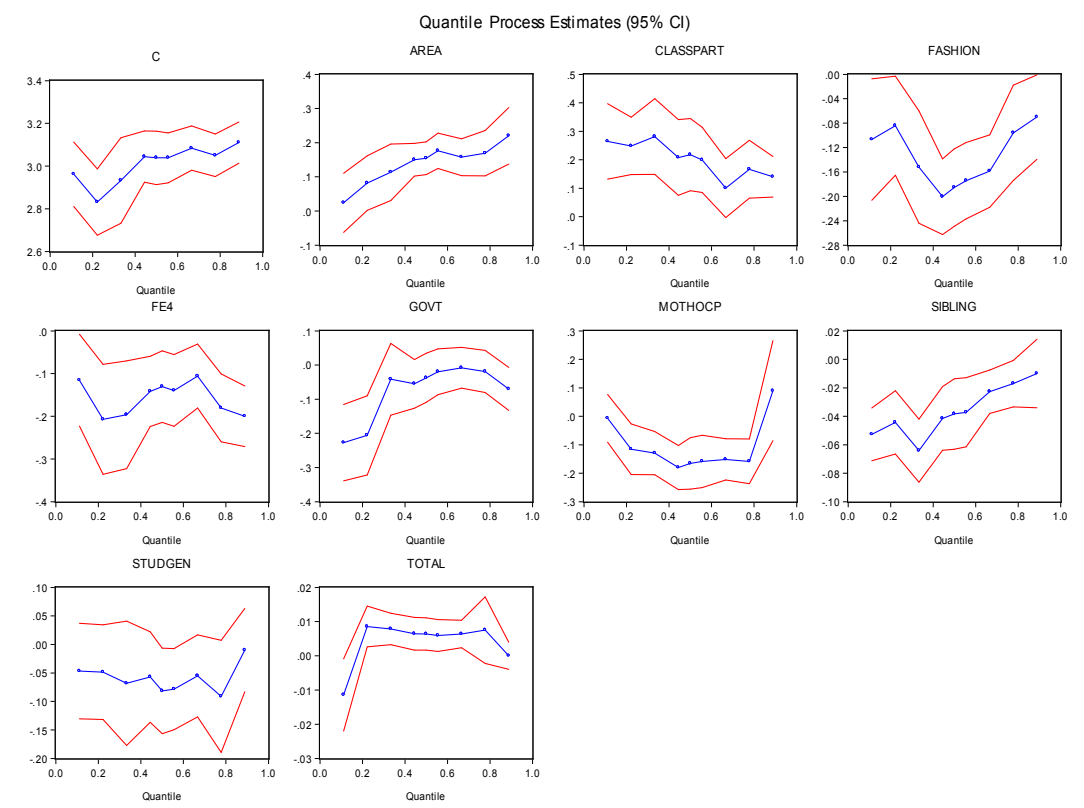

Figure 1: Estimate and 95\% Confidence Intervals of the Quantile Regression

Quantile has taken on $\mathrm{X}$-axis while $\mathrm{Y}$-axis consist the values of coefficient. Intercept graph shows as quantile increases value of coefficient also increases. Overall, it is showing an increasing trend. On $1^{\text {st }}$ quantile coefficient value is high and on $2^{\text {nd }}$ it goes down but onward it is showing increasing trend. Coefficients of area keep on increasing as quantiles increasing. At lower quantile 0.1 coefficient values is low but as quantiles increases value of coefficient increases also at $8^{\text {th }}$ quantile it comes down and again at $9^{\text {th }}$ quantile it goes up. Coefficients values of class participation with respect to quantiles showing a decreasing trend. From $2^{\text {nd }}$ to $4^{\text {th }}$ quantile it increases and then starts declining from $5^{\text {th }}$ to $7^{\text {th }}$ quantile and again goes up on higher quantiles. Coefficients of fashion are showing an unusual pattern with the increase of quantiles. For first two lower quantiles, value of coefficients increase and suddenly go down at $5^{\text {th }}$ quantile and then again start increasing and reach at maximum at 
highest $9^{\text {th }}$ quantile.Coefficients of father education are showing a zigzag pattern. At first quantile, it goes up and meet highest value at $7^{\text {th }}$ quantile and declines again. Coefficients of government employment policy are showing an increasing pattern as quantiles increases. It is low at beginning then increases and reaches at peak on fourth quantile. Coefficients values bit fall at $5^{\text {th }}$ quantile but later on show increasing trend. Coefficient values of mother occupation are showing a bathtub shape. These are high at extreme quantiles on $1^{\text {st }}$ and $9^{\text {th }}$ but smooth in between. Sibling's coefficient values are also exposing an upward trend. Coefficients only fall at $4^{\text {th }}$ quantilewhile on remaining quantiles showing high values. Student gender coefficients representing a crisscross outline of coefficients at different quantiles. However, amazingly the values are low at $1^{\text {st }}$ lower quantile and high at $9^{\text {th }}$ quantile.

\section{Conclusions}

There are convinced inferences for guiding principle supported by above empirical estimation results and findings. Firstly, it found that the level of father educational, mother occupation, and the sibling's presence have major and negative impact on student performance that pointed out that the major variations in student performance are due to family inputs not by institute's inputs. It is very evident that factors related to family emerged more visible than that factors come under institute.

Chen et al. (2011) also mentioned that working mother status put very negative effect on student performance. Highlighting regional differences impact on student's performance is one of the most vital intention of this research. The average effect of 0.124 for the urban and rural difference puts forward the idea that the average performance of urban students is higher than that of rural students. It is also noticed that at lower quantile, area plays significant role in the output of the students. These results also match with the study of Chen et al. (2011).Student gender is an insignificant variable at extreme lower and upper quantiles but negatively related and significant according to linear regression. It means for acute performers, gender does not matter. A gap between the performance of boys and girls has been found at $(\tau=0.5,0.6)$, where girls showing better performance than boys. The CGPAs of girls are good than that of boys. Chambers and Schreiber (2004) also inferred the same results that female students hit to good educational performance as 
compared to male student. However, educational activities and more time in study could help gaining good marks. In addition, an interesting result is also found that the more the time spent doing homework, the better the scores. Caldas and Bankston (1997) also drew the same findings. Study concludes that class participation is positively link with student performance while passion for fashion is negatively linked. As much, a student takes part in class discussion it will nourish his/her concepts and save time from messing up on fashion, will result in good performance. Due to uncertain employment policies, students do not try to perform well. They wish to settle their own business instead of salary base job. Both linear regression and quantile regression show that government employment policy correlate in a negative way with student performance particularly. It is also observed that coefficients are different across quantile values and conditional quantiles are not equal i.e., different factors do not have same affect at each quantile or would say low, middle and high achievers are effected in different manner.

\section{Recommendations}

Based on the findings, It is recommended that government should invest resources ignoring urban-rural regions. The study suggests universities should place much greater importance on self-study, and on make sure that students are performing professionally in all regions. Teachers need to develop strategies to provide motivational support, enhance the classroom level interactions like teacher to student and student-to-student interactions, and improve the quality of the instruction for all students on equal base regardless the difference between high performance and low performance students.

\section{Limitations of the Study}

The results of this study give a snap shot of public and private universities of Lahore. This research can be extended for B.A/B.Sc (HONS.) student's data from universities in Pakistan. Other degree programs and disciplines can also be studied. In addition, the same study can conducted at higher secondary, secondary and primary level. 


\section{References}

Caldas, S.J., \& Bankston, C. (1997).Effect of school population socioeconomic status on individual academic achievement, Journal of Educational Research, 90(5), 43-55.

Chambers, E. A.,\& Schreiber, J. B. (2004). Girl's academic achievement: varying associations of extracurricular activities, Gender and Education, 16(3), 327-346.

Changhui, K. (2006). Classroom peer effects and academic achievement: quasi-randomization evidence from South Korea, Journal of Urban Economics, 61(3), 458-495.

Chen, S., Kuo, H., \& Chen C. (2011). Estimating the extreme behaviors of student's performance using quantile regression-evidences from Taiwan, Education of Economics,20(1), 93-113.

Crosnoe, R., Johnson, M. K.,\& Elder, G. H. (2004). School size and the interpersonal side of education: an examination of race/ethnicity and organizational context, Social Science Quarterly, 85(5), 1259-1274.

Diaz, A. L. (2003). Personal, family and academic factors affecting low achievement in secondary school, Electronic Journal of Research in Educational Psychology and Psycho pedagogy, 1(1), 43-66.

Dustmann, C., \& Soest, A.V. (2007). Part-time work, school success and school leaving, Empirical Economics, 32(2-3), 277-299.

Eide, E., \&Showalter, M.H. (1997). The effect of school quality on student performance: A quantile regression approach, Economics Letters, 58(1) 345-350.

Goddard, R. D. (2003). Relational networks, social trust, and norms: asocial capital perspective on student's chances of academic success. Educational Evaluations and Policy Analysis, 25(1), 59-74. 
Hanushek, E.A. (1971). Teacher characteristics and gains in student achievement; estimation using micro data, The American Economic Review, 61(2), 280-288.

Hijaz, S. T.,\& Naqvi, S. M. M. R. (2006). Factors affectingstudent's performance: a case of private colleges of Bangladesh, e-Journal of Sociology, 3(1), 1-10.

Levin, J. (2001). For whom the reductions count: a quantile regression analysisof class size and peer effects on scholastic achievement, Empirical Economics, 26(1), 221-246.

McCaffrey, D. F., Lockwood, J. R., Koretz, D., Louis, A.T., \& Hamilton, L. (2004). Models for value-added modeling of teacher effects, Journal of Educational and Behavioral Statistics, 29(1), 67-101.

Murunga, Z., Indoshi, F., \& Okwach, T. (2019). Influence of teacher related factors on students' academic performance in Kiswahili composition in public secondary schools in Kisumu west sub-county, Kenya. European Journal of Education Studies, 6(7). doi: 10.5281/zenodo. 349118

Koenker, R.,\& Bassett, G. W. (1978). Regression quantiles, Econometrica, 46(1), 33-50.

Mobegi, Ondigi, B.,\&Oburu, O. (2010). Secondary school head teachers' quality assurance strategies and challenges in Gucha district, Kenya, Education Research and Reviews, 5(7), 408-414.

Oettinger, G.S. (1999). Does high school employment affect high school academic performance? Industrial and Labor Relations Review, 53(1), 136-151.

Orodho, A.J. (2014). Coalescing nutrition and health programs to enhance pupils' participation in basic education as a panacea to socio-economic development of marginalized communities in Kenya in the 21st century, a paper presented the Africa Nutrition Conference, North Coast Beach Hotel Mombasa, Kenya, 10-11. 
Ruhm, C.J. (1995). The extent and consequences of high school employment, Journal of Labor Research, 16(3), 293-304.

Stinebrickner, R., \& Stinebrickner, T.R. (2004). Time use and college outcomes, Journal of Econometrics, 121(1-2), 243-269.

Sengul, O., Zhang, X., \& Leroux, A. J. (2019). A multi-level analysis of students' teacher and family relationships on academic achievement in schools. International Journal of Educational Methodology, 5(1), $117-133$

Suhaini, M., Ahmad, A., \& Harith, S. H. (2020). Factors influencing student achievement: systematic review. International Journal of Psychosocial Rehabilitation, 24(5), 550-560.

Tian, H., \& Sun, Z. (2019). Survey report on factors influencing students' academic achievement. Assessment report on Chinese primary school students' academic achievement, 253-302 doi:10.1007/978-3-662-57530-7_6.

Tyler, J.H. (2003). Using state child labor laws to identify the effect of school-year work on high school achievement, Journal of Labor Economics, 21(2), 353-380.

Victor, S., \& Mweru, M. (2019). Influence of parental level of education on their involvement in pre-school children's educational activities in Sikalame zone, Siaya County, Kenya. European Journal of Education Studies, 6(7).

\section{Citation of this Article:}

Ishtiaq, S., Mahmood, Y., \& Khan, H. (2019). Acute performance estimation of students using quantile regression approach (A case study of Lahore). Pakistan Journal of Education, 36(3), 01-18.

DOI: $10.30971 /$ pje.v36i3.850.g207

To link this article: http://dx.doi.org/10.30971/pje.v36i3.850 